\title{
Sensitivity of quantitative sensory models to morphine analgesia in humans
}

\author{
Anne Estrup Olesen ${ }^{1,2}$ \\ Christina Brock ${ }^{1,2}$ \\ Eva Sverrisdóttir ${ }^{2}$ \\ Isabelle Myriam Larsen' \\ Asbjørn Mohr Drewes',3 \\ 'Mech-Sense, Department of \\ Gastroenterology and Hepatology, \\ Aalborg University Hospital, \\ Aalborg, Denmark; ${ }^{2}$ Department \\ of Drug Design and Pharmacology, \\ Faculty of Health and Medical \\ Sciences, University of Copenhagen, \\ Copenhagen, Denmark; ${ }^{3}$ Department \\ of Clinical Medicine, Aalborg \\ University, Aalborg, Denmark
}

This article was published in the following Dove Press journal: Journal of Pain Research

9 December 2014

Number of times this article has been viewed

Introduction: Opioid analgesia can be explored with quantitative sensory testing, but most investigations have used models of phasic pain, and such brief stimuli may be limited in the ability to faithfully simulate natural and clinical painful experiences. Therefore, identification of appropriate experimental pain models is critical for our understanding of opioid effects with the potential to improve treatment.

Objectives: The aim was to explore and compare various pain models to morphine analgesia in healthy volunteers.

Methods: The study was a double-blind, randomized, two-way crossover study. Thirty-nine healthy participants were included and received morphine $30 \mathrm{mg}(2 \mathrm{mg} / \mathrm{mL})$ as oral solution or placebo. To cover both tonic and phasic stimulations, a comprehensive multi-modal, multitissue pain-testing program was performed.

Results: Tonic experimental pain models were sensitive to morphine analgesia compared to placebo: muscle pressure $(F=4.87, P=0.03)$, bone pressure $(F=3.98, P=0.05)$, rectal pressure $(F=4.25, P=0.04)$, and the cold pressor test $(F=25.3, P<0.001)$. Compared to placebo, morphine increased tolerance to muscle stimulation by $14.07 \%$; bone stimulation by $9.72 \%$; rectal mechanical stimulation by $20.40 \%$, and reduced pain reported during the cold pressor test by $9.14 \%$. In contrast, the more phasic experimental pain models were not sensitive to morphine analgesia: skin heat, rectal electrical stimulation, or rectal heat stimulation (all $P>0.05$ ).

Conclusion: Pain models with deep tonic stimulation including $\mathrm{C}$ fiber activation and and/or endogenous pain modulation were more sensitive to morphine analgesia. To avoid false negative results in future studies, we recommend inclusion of reproducible tonic pain models in deep tissues, mimicking clinical pain to a higher degree.

Keywords: pain, opioid, experiment pain model

\section{Introduction}

Opioid treatment of clinical pain challenges clinicians due to variable individual responses. This has resulted in continuous research in analgesic effects and underlying drug mechanisms. Confounders such as underlying diseases, comedication, and psychological status provide an inhomogeneous population in clinical studies, and therefore, it can be complicated to demonstrate analgesic effects. In contrast, human experimental pain models offer opportunities to evaluate underlying analgesic mechanisms in standardized laboratories, where reproducible stimuli can be applied and the pain can be assessed quantitatively. ${ }^{1}$ However, human experimental pain studies have also demonstrated variable results regarding opioid effects, and not all compounds with known analgesic properties are effective in all experimental models. ${ }^{2,3}$ Therefore,

Correspondence: Anne Estrup Olesen Mech-Sense, Department of Gastroenterology and Hepatology, Aalborg University Hospital, Mølleparkvej 4, Aalborg, Denmark Tel +4597663523

Email aneso@rn.dk 
identification of appropriate experimental pain models can be critical for facilitating the rational clinical development of novel analgesic compounds and drug formulations. ${ }^{4}$

To assess several elementary attributes of the stimuli in the experimental pain model, it has been recommended to use a battery of stimulations (multi-modal) in several tissues (multi-tissue), rather than a single stimulation. ${ }^{5}$ This approach will complicate the experimental procedure, emphasizing the importance of having consistent, standardized laboratory facilities and experienced research staff available, providing reliable methods. ${ }^{1}$ Identifying combinations of experimental models and clinical validation seems to be the direction for the development of experimental pain models toward predictive tools in drug development. ${ }^{6}$

The different methods can be divided into phasic and tonic models based on the nature and duration of the different methods. ${ }^{7,8}$ Phasic pain models induce fast and sharp pain predominantly transmitted by $\mathrm{A} \delta$ fibers; whereas tonic pain models induce slow and dull pain transmitted primarily by C fibers. ${ }^{7,8}$ Animal studies have demonstrated that opioids preferentially attenuate nociceptive responses produced by C fiber activation. ${ }^{9,10}$ Additionally, human studies have shown that pain models including $\mathrm{C}$ fiber activation and/or characterization of endogenous pain modulation and/or increased affective component are more sensitive to opioids. ${ }^{1}$ Despite this, most investigations on analgesic effects have been performed using models of phasic pain in superficial tissues. ${ }^{2}$

Therefore, the aim was to investigate the effect of the gold standard opioid, morphine, on a battery of phasic and tonic pain stimulations in a multi-modal, multi-tissue, human experimental pain study in a group of healthy volunteers.

\section{Methods}

The Ethics Committee for the Region of Northern Jutland (reference no N-20100046) and the Danish Medicines Agency (reference no 2612-4319) approved the study, which was carried out in the Research Laboratory at MechSense, Department of Gastroenterology, Aalborg University Hospital, Aalborg, Denmark. The study was conducted in the period November 2010 to April 2012.

The trial was registered at ClinicalTrials.gov (ClinicalTrials.gov identifier: NCT01245244, EUDRACT no 2010-020894-17). The study was monitored according to the rules of Good Clinical Practice (GCP) by the GCP unit Aarhus University Hospital, Aarhus, Denmark.

\section{Participants}

Forty participants were enrolled by a medical doctor, gave their informed consent and were compensated for participation. Inclusion criteria were: 1) age between 20 and 65 years; 2) opioid naïve, ie, has not recently taken an opioid medication regularly; 3 ) no known allergy to study medication; 4) no ongoing participation in other drug studies; 5) not pregnant; 6) no previous addictive behavior; 7) no previous pain causing diseases or psychiatric disorders. All included woman were on safe contraceptive medication during the study. Before inclusion, a medical doctor conducted a routine health screening for each participant, ruling out any pain-related conditions.

\section{Study protocol}

A double-blind, randomized, two-way crossover, single-dose study was conducted with at least 1 -week washout intervals. A pharmacist not involved in the study generated a randomization list by http://www.randomization.com; all participants were randomized into four blocks to receive morphine or placebo on day 1 or day 2. The same pharmacist handled the morphine oral mixture and secured and documented that all participants received the correct medication for specific periods. Thus, the experimenters and the participants were fully blinded for randomization. One-week washout intervals were chosen to ensure that the morphine was fully excreted before the second study period. Each participant fasted at least 6 hours prior to the study. Prior to the first dosing day, a training session, including all experimental pain procedures was conducted, in order to familiarize the participants with the laboratory environment and to verify that the participants could tolerate the comprehensive experimental pain-testing procedure. The study was controlled for menstrual cycle so that each woman was investigated in the same phase of her individual menstrual cycle. All testing was performed by well-trained experimenters in a quiet room. The same experimenter tested each participant at the same time of the day on both study days.

\section{Medication}

Each participant received morphine $30 \mathrm{mg}(2 \mathrm{mg} / \mathrm{mL})$ as an oral solution or placebo. The color and taste of the solution was masked by adding $5 \mathrm{~mL}$ of orange juice concentrate to the solution; hence, the total amount of one dose was $20 \mathrm{~mL}$ (15 mL morphine solution or pure water [placebo] and $5 \mathrm{~mL}$ of orange juice). Oral solution was used instead of tablets to avoid variability in dissolution of the tablets.

\section{Pain assessment}

Somatic stimulations were interrupted when the participant reported "pain tolerance threshold" (PTT). A modified numerical/categorical analog scale for assessment of 
nonpainful and painful sensations was used for the rectal stimulations and for the cold pressor stimulation. The scale is a continuous scale from 0 to 10 , where $5=$ the pain detection threshold (PDT). This scale has been validated for reliability and robustness, and is described in detail elsewhere. ${ }^{11}$

\section{Pain-testing procedures}

A comprehensive multi-modal, multi-tissue, pain-testing program was performed, including pain thresholds and pain intensity ratings. A variety of pain models were selected to cover both superficial and deep pain as well as phasic and tonic stimulations (Table 1 and Figure 1). Hereby, sufficient resting periods were included in the protocol and the risk for sensitization was diminished.

\section{Skin stimulation}

\section{Thermal}

Thermal heat stimuli were applied by a contact heat-evoked potential stimulator (CHEPS; Medoc Ltd, Ramat Yishai, Israel), placed $10 \mathrm{~cm}$ distal to the elbow on the right forearm. The start temperature was set to $32^{\circ} \mathrm{C}$ and the temperature increase was set at $1{ }^{\circ} \mathrm{C} / \mathrm{s}$. Participants were asked to press a button at PTT, and immediately afterward, the thermode cooled down to $32^{\circ} \mathrm{C}$, with a cooling rate of $10^{\circ} \mathrm{C} / \mathrm{s}$. This was repeated three times, and the average stimulus intensity $\left({ }^{\circ} \mathrm{C}\right)$ was calculated and used for further data analysis.

\section{Muscle stimulation}

\section{Mechanical}

Pressure was applied to the supinator muscle on the left forearm, $15 \mathrm{~cm}$ distal to the elbow by a handheld electronic pressure algometer (Somedic AB, Stockholm, Sweden) with a standard probe of $1 \mathrm{~cm}^{2}$. The pressure increase rate was $30 \mathrm{kPa} / \mathrm{s}$ and the algometer was set with a safety maximum of 2,000 $\mathrm{kPa}$. The stimulation was interrupted when the participants reported PTT and the maximum

Table I Overview of included pain models

\begin{tabular}{llll}
\hline Tissue & Modality & Structure & Duration \\
\hline Skin & Thermal & Superficial & Phasic \\
& Cold pressor test & Deep & Tonic \\
Muscle & Mechanical & Deep & Tonic \\
Bone & Mechanical & Deep & Tonic \\
Viscera & Electrical & Deep & Phasic \\
& Thermal & & Phasic \\
& Mechanical & & Tonic \\
\hline
\end{tabular}

Notes: Models are assigned to the tissue predominantly affected. It should be noted that the cold pressor test is not true skin stimulation, but it will affect skin nociceptors as well and is therefore assigned to skin in this table. stimulus intensity $(\mathrm{kPa})$ was noted and used for further analysis.

\section{Bone stimulation}

\section{Mechanical}

The mechanical stimulation was conducted on the right tibia bone, $10 \mathrm{~cm}$ distal to the patella by a handheld electronic pressure algometer (Somedic $\mathrm{AB}$ ) with a specially designed probe of $3.1 \mathrm{~mm}^{2}$ (Aalborg University, Aalborg, Denmark). This probe has been validated in previous studies. ${ }^{12,13}$ The pressure increase rate was $999 \mathrm{kPa} / \mathrm{s}$. Stimulation was interrupted when PTT was reported. The maximum stimulus intensity $(\mathrm{kPa})$ was noted and used for further analysis.

\section{Visceral stimulation}

For rectal stimulation, a custom-designed probe (Ditens, Egaa, Denmark) with a polyester urethane bag for mechanical and thermal stimulation, and stainless steel electrodes for electrical stimulation was used. The rectal probe has been validated and is described in detail elsewhere. ${ }^{14}$ Prior to the experiment, a $5 \mathrm{~mL}$ enema with $2 \mathrm{mg} / \mathrm{mL}$ bisacodyl (Toilax ${ }^{\circledR}$; Orion Pharma, Espoo, Finland) was administered. A lubricated anoscope (Cat No E-03. 19. 925; Heine Optotechnik, Herrsching, Germany) was placed in the anal canal and through this, the probe was placed in the rectum $20 \mathrm{~cm}$ from the anal sphincter. All data were displayed online (Openlab; GMC, Hornslet, Denmark) and stored for later analysis.

\section{Mechanical}

For mechanical stimulation of the rectum, the bag was inflated with $37^{\circ} \mathrm{C}$ water from a water bath (Julabo VWR 5; Julabo, Labortechnik GMBH, Seelbach, Germany) controlling the temperature. A peristaltic pump (Type 111; Ole Dich Instrumentmakers, Hvidovre, Denmark) was used to inflate the bag at a rate of $200 \mathrm{~mL} /$ minute. Three distensions to the PDT were performed with a 1-minute interval to precondition the tissue. Hereafter, a single distension to "moderate pain" was performed. The bag was emptied at the same rate as it was inflated. The volumes in the bag $(\mathrm{mL})$ at PDT and at moderate pain were noted and used for further analysis.

\section{Electrical}

For the electrical stimulation, two stainless steel bipolar electrodes mounted on the tip of the rectal probe with an inter-electrode distance of $2 \mathrm{~mm}$ were connected to a computer-controlled constant current stimulator (Digitimer Ltd, Welwyn Garden City, UK). Impedance was kept below $3 \mathrm{k} \Omega$ to ensure sufficient mucosal contact. The electrical 

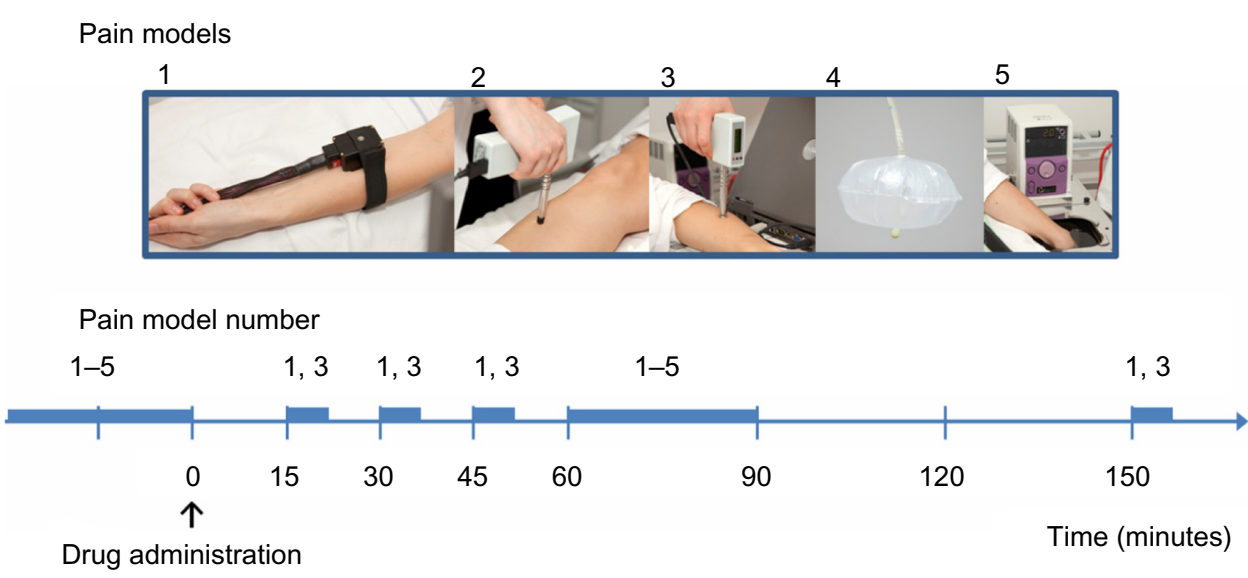

Figure I Graphical overview of the experimental procedure.

Notes: Included pain models (upper) and flowchart (lower) are illustrated. Included pain models were: I) skin heat; 2) bone pressure; 3) muscle pressure; 4) visceral stimulations, and 5) the cold pressor test. Stimulations were applied in the indicated order $(1 \rightarrow 2 \rightarrow 3 \rightarrow 4 \rightarrow 5)$ at baseline and 60 minutes after drug administration. Skin I) and muscle 3) stimulations were performed at several time points (0, 15, 30, 60, and 150 minutes after drug administration). Blue bars on flowchart indicate duration of test battery. The full battery (I-5) lasted approximately 30 minutes. Skin and muscle stimulation lasted approximately 7 minutes in total.

stimulation intensity slowly increased in increments of $1.0 \mathrm{~mA}$ increments. To blind the participant, sham stimulations with same or lower intensities were included. Stimulus intensities $(\mathrm{mA})$ at PDT and at moderate pain were noted and used for further analysis.

\section{Thermal}

Before thermal stimulation, $60 \mathrm{~mL}$ of $37^{\circ} \mathrm{C}$ water was added to the polyester urethane bag of the probe. The temperature elevation was reached by recirculation of $68^{\circ} \mathrm{C}$ water through the bag. A water bath (VWR 5; Julabo) controlled the temperature in the closed circuit. A peristaltic pump (Type 111; Ole Dich Instrumentmakers) circulated the water at a flow rate of $150 \mathrm{~mL} /$ minute, and a temperature sensor (Buhl \& Bønsøe AS, Virum, Denmark) was located in the inflated bag. During thermal stimulation, the anal canal was shielded with the anoscope in order to minimize stimulation of somatic tissue. The temperature increased until the participants reported moderate pain, and immediately hereafter, the heated water was withdrawn to minimize discomfort for the participant. Thermal stimulus was computed as area under the timetemperature curve.

\section{Cold pressor test}

For the cold pressor stimulation, a cold pressor test apparatus (Grant instruments; Fischer Scientific, Slangerup, Denmark) was used. The participants immersed their left hand into the $2^{\circ} \mathrm{C}$ cooled water up to the wrist for 2 minutes. The participants rated the perceived pain continuously on the electronic handheld device.

\section{Statistical analysis}

All data were baseline corrected before statistical analysis. Thus, data for statistical analysis represent individual relative changes from baseline values expressed as percentages. Coefficients of difference between treatments and associated confidence intervals were provided for time point 60 minutes.

For statistical comparison of placebo versus morphine effects on thermal skin stimulation and mechanical muscle stimulation, data were analyzed by two-way repeated measures analysis of variance (ANOVA), as these assessments were performed at several time points $(15,30,45,60$, and 150 minutes after drug administration) in each study arm. Factors for these two-way ANOVAs were: 1) treatment and 2) time. For rectal electrical and mechanical stimulations, analyses were performed at two pain levels (PDT and moderate pain). These data were analyzed by two-way ANOVA, where factors were: 1) treatment and 2) pain level. When outcome measures were only assessed at one time point (60 minutes after drug administration), one-way ANOVA was used for statistical analysis (mechanical bone stimulation, rectal thermal stimulation, and the cold pressor test). Stata software (v12.1) was used for analysis. $P$-values of $<0.05$ were considered significant.

As this study investigated the effects of morphine on multiple endpoints, a precise calculation of sample size for each endpoint was not possible. A sample size was estimated based on data from a previous study, from our group, ${ }^{27}$ of opioid effect assessed by heat stimulation of the skin in healthy volunteers, as skin heat stimulation was hypothesized to be the least sensitive outcome. To detect a difference of $4 \%$ in 
analgesic effect between placebo and morphine, 40 subjects should be included (alpha $=0.05$, power $=0.90)$.

\section{Results}

The study was conducted over 18 months over the period October 2010 to April 2012, during which 93 healthy volunteers were screened for participation and 39 (18 females and 21 males; average age: 26.9 \pm 6.5 years) completed the study (Figure 2). Forty-nine participants were initially included; ten of these were dropouts due to different reasons. Nine dropouts took place at the training session, before randomization. Thus, only one participant dropped out after randomization, and the balance of the study was reserved. Thirty-nine participants finalized the study and were included in further analyses.

\section{Side effects}

Three participants experienced morphine side effects to such a degree that the experiment was interrupted. They reported dizziness, tiredness, and intense pain in the epigastrium radiating to both sides. In total, 26 of 39 participants experienced side effects due to the morphine treatment (nine reported nausea, 23 reported dizziness, four reported itching, and two reported sweating). Eight out of 39 participants experienced side effects in the placebo arm (five reported nausea, four dizziness, and one itching).

\section{Dynamic effects}

Thirty-nine participants completed both experimental sessions. However, not all of them completed all tests on both days, due to technical challenges such as equipment failure or balloon leakage on the rectal probe. For the cold pressor test, only participants who tolerated 2 minutes conditioning stimuli were included in the analysis and those who withdrew their hand before 2 minutes were excluded. Total numbers of participants included in each analysis are provided in Table 2, which provides an overview of the results. Subanalyses of sex-related differences in morphine responsiveness were performed for each dynamic endpoint; however, no differences were found (all $P>0.05$ ).

For all significant outcomes, coefficients of significant differences between placebo and morphine and associated confidence intervals for effects at the 60-minute time point are provided in Table 3.

\section{Skin stimulation}

\section{Thermal}

Thirty-seven participants completed the skin heat stimulation test at both experimental sessions. No difference was found between placebo and morphine $(F=0.21, P=0.65)$.

\section{Muscle stimulation Mechanical}

Thirty-nine participants completed the muscle pressure stimulation test at both experimental sessions. In comparison to placebo, morphine increased pain thresholds to muscle pressure over time ( $F=4.87, P=0.03)$. The effect started at 30 minutes and reached the maximum at 45 minutes, remaining effective until the end of the examination period (150 minutes; Figure 3).

\section{Bone stimulation}

\section{Mechanical}

Thirty-nine participants completed the bone pressure stimulation at both experimental sessions. Morphine increased pain

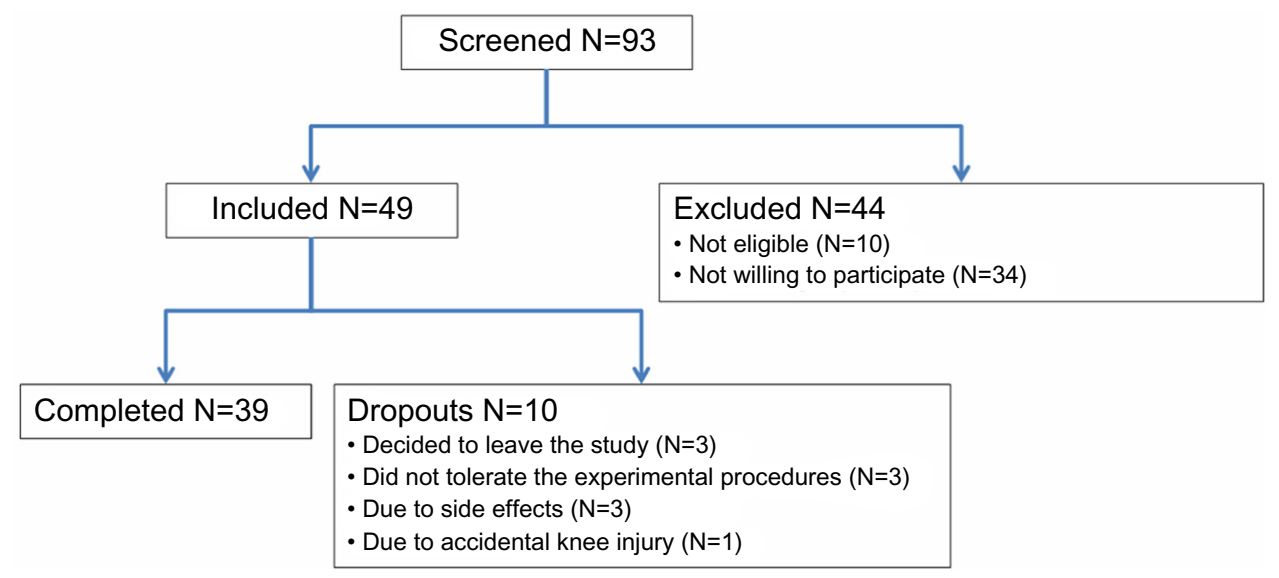

Figure 2 Flow diagram of the study.

Notes: The diagram explicitly shows the number of screened, excluded, included, dropout, and completed participants. All completed participants were included in the primary data analysis. 
Table 2 Results for all investigated pain stimulations given as mean values and confidence intervals

\begin{tabular}{|c|c|c|c|c|c|c|c|c|}
\hline \multirow[t]{2}{*}{ Tissue } & \multirow[t]{2}{*}{ Modality } & \multirow[t]{2}{*}{$\mathbf{N}$} & \multirow{2}{*}{$\begin{array}{l}\text { Time } \\
\text { (minute }\end{array}$} & \multirow{2}{*}{ Score } & \multicolumn{2}{|l|}{ Placebo } & \multicolumn{2}{|c|}{ Morphine } \\
\hline & & & & & Mean & $\mathrm{Cl}$ & Mean & Cl \\
\hline \multirow[t]{6}{*}{ Skin } & Thermal $\left({ }^{\circ} \mathrm{C}\right)$ & 37 & 0 & 7 & 45.15 & $44.39-45.91$ & 45.09 & $44.24-45.95$ \\
\hline & & & 15 & 7 & 44.66 & $43.83-45.49$ & 44.82 & $44.03-45.61$ \\
\hline & & & 30 & 7 & 45.13 & $44.32-45.93$ & 45.15 & $44.32-45.97$ \\
\hline & & & 45 & 7 & 45.18 & $44.41-45.96$ & 45.20 & $44.39-46.01$ \\
\hline & & & 60 & 7 & 45.20 & $44.40-46.00$ & 45.34 & $44.47-46.21$ \\
\hline & & & 150 & 7 & 44.89 & $44.07-45.72$ & 44.88 & $44.00-45.76$ \\
\hline \multirow[t]{6}{*}{ Muscle } & Mechanical $(\mathrm{kPa})$ & 39 & 0 & 7 & 497.59 & $440.85-554.33$ & 490.28 & $430.4 I-550.15$ \\
\hline & & & 15 & 7 & 508.67 & $443.64-573.69$ & 515.00 & $438.70-591.30$ \\
\hline & & & 30 & 7 & 506.23 & $449.54-562.92$ & 536.28 & $463.28-609.29$ \\
\hline & & & 45 & 7 & 511.26 & $442.90-579.61$ & 585.15 & $486.46-683.85$ \\
\hline & & & 60 & 7 & 511.49 & $447.81-575.17$ & 581.90 & $486.5 \mathrm{I}-677.28$ \\
\hline & & & 150 & 7 & 480.72 & $421.56-539.88$ & 566.64 & $48|.55-65| .73$ \\
\hline \multirow[t]{2}{*}{ Bone } & Mechanical $(\mathrm{kPa})$ & 39 & 0 & 7 & $5,651.61$ & $5,036.30-6,266.92$ & $5,814.69$ & $5,075.64-6,553.74$ \\
\hline & & & 60 & 7 & $5,489.38$ & 4,807.35-6,|7|.4| & $6,054.62$ & $5,343.33-6,765.92$ \\
\hline \multirow[t]{6}{*}{ Rectal } & Electrical (mA) & 30 & 0 & 7 & 32.3 & $27.25-37.35$ & 28.8 & $23.90-33.70$ \\
\hline & & & 60 & 7 & 33.57 & $28.04-39.09$ & 30.83 & $25.64-36.03$ \\
\hline & Mechanical (mL) & 36 & 0 & 7 & 211.85 & $|82.5|-24 \mid .19$ & 201.57 & | 70.87-232.28 \\
\hline & & & 60 & 7 & 223.15 & $|94.80-25| .49$ & 240.09 & $207.92-272.26$ \\
\hline & Thermal $\left(A \cup C^{a}\right)$ & 38 & 0 & 7 & 174.16 & $131.16-217.16$ & 146.88 & $109.33-184.44$ \\
\hline & & & 60 & 7 & $|67.8|$ & | 33.17-202.44 & 151.06 & $109.06-193.05$ \\
\hline \multirow[t]{2}{*}{ Cold pressor test } & Thermal $\left(A \cup C^{b}\right)$ & 34 & 0 & na & 852.50 & $796.54-908.47$ & 867.06 & $812.84-921.27$ \\
\hline & & & 60 & na & 856.35 & $800.98-911.72$ & 799.12 & $735.64-862.59$ \\
\hline
\end{tabular}

Notes: Results are given as absolute values for mean and $\mathrm{Cl}$ for both placebo and morphine. Numbers of participants who completed each stimulation are given ( $\mathrm{N}$ ). Thirty-nine participants completed both experimental sessions. However, not all of them completed all tests on both days, due to technical challenges such as equipment failure or balloon leakage on the rectal probe. Skin stimulation temperature is given as degrees Celsius $\left({ }^{\circ} \mathrm{C}\right)$, mechanical pressure is given as kilopascals $(\mathrm{kPa})$, and electrical current is given as milliamperes $(\mathrm{mA})$. Visceral mechanical stimulation intensity is given as milliliters of water in the bag on the rectal probe $(\mathrm{mL})$ and visceral heat stimulation intensity is given as area under the temperature curve in ${ }^{\circ} \mathrm{C} \times$ seconds $\left(A \cup C^{a}\right)$. Pain intensity reported during cold stimulation is given as area under the pain-score-curve in pain-score $\times$ seconds $\left(A \cup C^{b}\right)$. Abbreviations: $\mathrm{AUC}$, area under the curve; $\mathrm{Cl}$, confidence interval; na, not applicable.

thresholds compared to placebo. However, this effect was at the border of significance ( $F=3.98, P=0.05$; Figure $4 \mathrm{~A})$.

\section{Visceral stimulation \\ Electrical}

Thirty participants completed the rectal electrical stimulation at both experimental sessions. No difference was found between placebo and morphine effects $(F=0.02$, $P=0.88)$.

\section{Mechanical}

Thirty-six participants completed the rectal mechanical stimulation at both experimental sessions. Morphine

Table 3 Significant outcomes; coefficients of differences in percentage at the 60-minute time point

\begin{tabular}{lll}
\hline Stimulation & Coefficient & $\mathbf{9 5 \%} \mathbf{C l}$ \\
\hline Muscle mechanical & 14.07 & 1.64 to 26.49 \\
Bone mechanical & 9.72 & 0.02 to 19.42 \\
Rectal mechanical $^{\mathrm{a}}$ & 20.40 & 1.52 to 39.28 \\
Cold pressor test & -9.14 & -12.77 to $-5.5 \mathrm{I}$ \\
\hline
\end{tabular}

Notes: ${ }^{a}$ At pain detection threshold. The coefficient indicates the difference in percentage between morphine and placebo. Coefficients and $\mathrm{Cls}$ are given.

Abbreviation: $\mathrm{Cl}$, confidence interval. increased pain thresholds to rectal mechanical stimulation compared to placebo ( $F=4.25, P=0.04$; Figure 4B).

\section{Thermal}

Thirty-eight participants completed the rectal heat stimulation at both experimental sessions. No difference was found between placebo and morphine $(F=0.33, P=0.57)$.

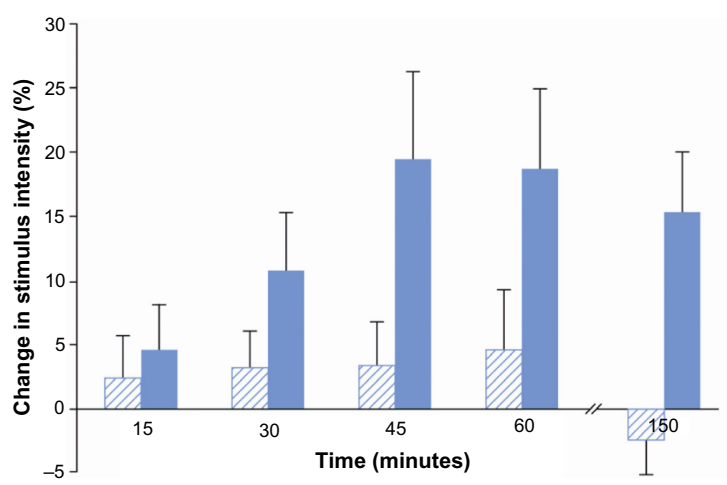

Figure 3 Analgesic effect on mechanical muscle stimulation.

Notes: Change in stimulation intensity from baseline value over time after placebo (shaded) or morphine (blue) treatment. Results are illustrated as changes in percentage (mean, standard error of the mean). The effect started at 30 minutes and reached the maximum at 45 minutes, remaining effective until the end of the examination period (150 minutes). 

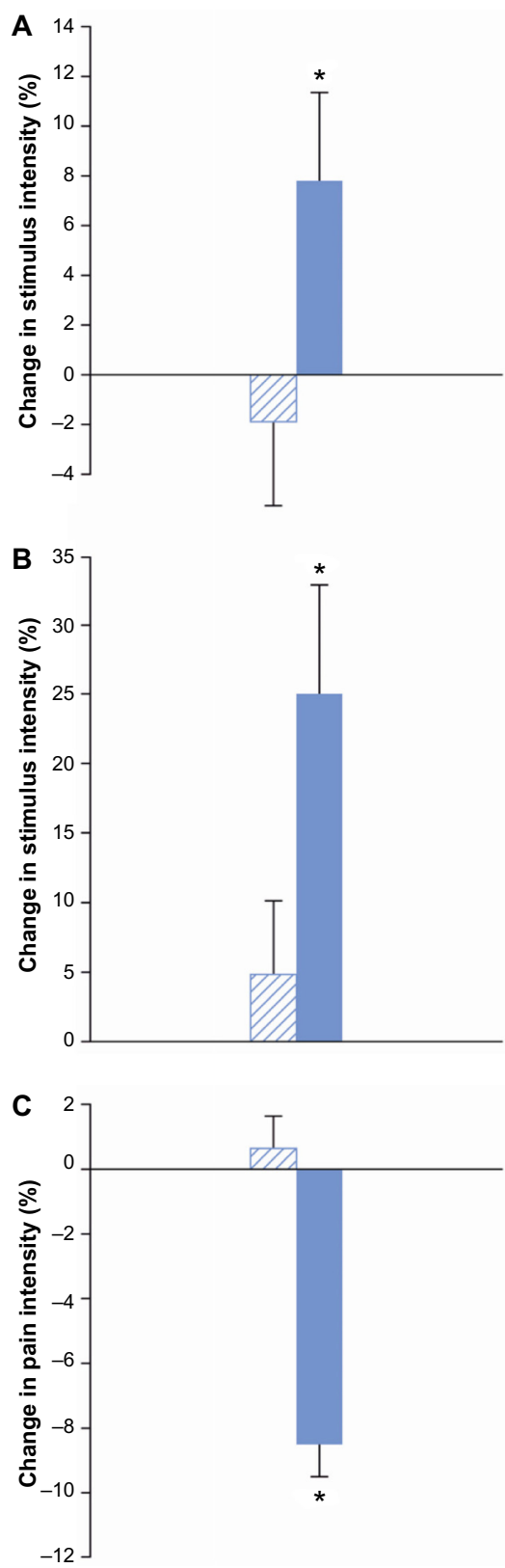

Figure 4 Analgesic effects.

Notes: Change in stimulation or pain intensity from baseline value after placebo (shaded) or morphine (blue) treatment. Results are illustrated as changes in percentage (mean, standard error of the mean), $* P<0.05$. (A) Morphine increased pain thresholds to bone pressure stimulation compared to placebo. This effect was at the border of significance; (B) morphine increased pain thresholds to rectal mechanical stimulation compared to placebo, and (C) morphine decreased pain ratings during cold pressor test compared to placebo.

\section{Cold pressor test}

Thirty-four participants completed the 2-minute cold pressor test. Morphine decreased pain ratings compared to placebo $(F=25.3, P<0.001$; Figure 4C).

\section{Discussion}

This is the first study that compares multi-modal and multitissue stimulations in the same experiment in a fairly large group of well-characterized healthy volunteers. We demonstrated that models including deep structure stimulations (muscle, bone, cold pressor, and rectum) with relatively long (tonic) duration were more sensitive to morphine analgesia than phasic and superficial models.

\section{Comparison between modalities Skin pain}

The method used for skin heat stimulation in the present study fulfilled previous recommendations. ${ }^{15}$ Despite this, it was not sensitive to morphine analgesia in the present study, as no difference was found between placebo and morphine. Opioid effects on heat pain have been tested through various stimulation paradigms and conflicting results exist. ${ }^{1,2}$ In the present study, the heat stimulation was stopped at moderate pain, meaning that it was more intense than a stimulus stopped at pain detection. It has been assumed that an $\mathrm{A}$ delta-mediated nociceptive component will show increasing dominance at high-intensity heating ${ }^{16}$ and it has previously been demonstrated that for heat stimulation, pricking pain by A delta fibers was felt at the end of the stimulation at high intensities. ${ }^{17}$ Therefore, in the present study, it could be speculated that A delta fibers were activated in the noxious range. Thus, the fact that no morphine analgesia was demonstrated may reflect the limited effectiveness of attenuating the A delta-mediated nociceptive component. Thus, in future experimental pain studies of morphine effects, it is not recommended to use high-intensity stimulations for heat stimulation of the skin by the method of limits. Instead, the heat PDT should be used. Furthermore, it is known that morphine will inhibit longer duration stimulation at lower doses than short duration stimulation, ${ }^{5}$ and it could be speculated that a higher dose of oral-administered morphine or an intravenous approach may be effective on skin heat pain. Finally, different thermodes were used in different studies, and even when the skin surface temperature is controlled, stimuli applied with different methods are not necessarily comparable. ${ }^{1,18}$

\section{Muscle pain}

Morphine reduced deep muscle pain in the present study. The majority of A delta and $\mathrm{C}$ fibers in muscles serve as polymodal nociceptors, ${ }^{19}$ and findings may be caused by a combined effect. This finding contradicted a previous study by Schulte et al, ${ }^{20}$ in which no morphine effect was seen in a deep muscle pain model. However, this study only included 15 healthy volunteers, and methods for pain induction were different as they used repeated 
intramuscular electrical stimulation and muscular infusion of hypertonic saline for induction of tonic muscle pain. In the present study, the maximum effect on muscle pressure pain was found 45 minutes after oral administration. Hence, the findings correspond well with the time it takes for morphine to reach the central nervous system, where the majority of opioid receptors in supraspinal components of the pain-modulating circuit are responsible for analgesic effect. ${ }^{21}$

\section{Bone pain}

Opioids are not the first choice of treatment for bone pain, but are often used when pain is intense and severe. ${ }^{22}$ Bone is innervated differently from the skin by $\mathrm{A}$ delta and $\mathrm{C}$ fibers. ${ }^{23}$ The terminals of these fibers mostly contain polymodal receptors. ${ }^{24}$ The posterium is therefore very sensitive to a variety of stimuli, where mechanical activation is the most clinically relevant. Thus, bone pressure was included in the present study as a model of pain stimulation in deep tissue. As the results were only marginally significant, bone pain stimulation may be less sensitive to opioid effects, and results should be more cautiously interpreted.

\section{Visceral pain}

In this study, a comprehensive visceral model, stimulating the rectum offered possibilities of multi-modal stimulations. The model has previously been shown to be reproducible ${ }^{14}$ and suitable for studying pharmacological interventions in healthy controls. ${ }^{14}$ External validity of the model of rectal distention has previously been demonstrated, as patients have reported that discomfort of pain induced by rectal distension was similar to their irritable bowel syndrome symptoms. ${ }^{25}$ In contrast, the model for electrical stimulation of the rectum is less relevant to a definable group of patients. Electrical pain is phasic, and intense electrical stimuli excites all peripheral fibers in a nondifferential fashion. ${ }^{8}$ Thus, analgesic effects of opioids on this dynamic endpoint have previously only been demonstrated in patients with chronic pain, suggesting that an upregulated pain system is needed for demonstration of analgesic effect. ${ }^{1}$ The most reliable proxy of thermal energy load to the tissue is assessment of the area under the temperature curve, ${ }^{26}$ which was used in the present study. However, no morphine analgesia could be demonstrated. This finding was supported by two previous visceral studies from our group, in which no effects of morphine were demonstrated when stimulating the esophagus with heat. ${ }^{27,28}$ Thus, the results may be explained by the phasic nature of this stimulation.

\section{Cold pressor pain}

Activation of descending inhibitory pathways preferentially attenuates $\mathrm{C}$ fiber activity, and exogenous opioids affect descending pain modulation..$^{29}$ Opioid sensitivity to the cold pressor model (affecting descending inhibitory pathways) has also previously been reported., ${ }^{3,30}$ Thus, the temporal configurations of the stimulus in addition to the different types of primary afferents being stimulated could contribute to the higher sensitivity of the cold pressor test to detect the analgesic effect of opioids. ${ }^{3}$

\section{Sensory versus affective pain}

Different modalities of experimental noxious stimuli can also be described according to their characteristic contributions to the sensory and affective components of the evoked pain. ${ }^{31}$ For example, the unpleasantness evoked by heat and electrical stimulation of the skin was less than that evoked by the cold pressor test, ${ }^{31}$ suggesting that tonic pain models affect these psychophysical parameters (eg, anxiety and catastrophizing) to a higher degree and consequently mimic clinical pain to a higher degree. It has been suggested that morphine more potently attenuates the affective component as compared to the sensory component. ${ }^{32,33}$ Hence, the cold pressor test, which is very sensitive to morphine, is known to involve strong affective and autonomic components. ${ }^{34}$

\section{Methodological considerations}

In the present study, all primary endpoints (tonic pain stimulations) provided significant results and no adjustment for multiplicity was made. ${ }^{35}$ It is well-known that different opioids exert different mechanisms in both experimental and clinical settings. ${ }^{36}$ Additionally, different administrations and dosing intervals will affect the outcome. Hence, it cannot be excluded that other findings would be seen if different opioids or doses were administered. It should therefore be emphasized that this discussion was based exclusively on a single oral dose of morphine if nothing else was stated.

Dropouts in quantitative sensory testing studies are not unusual. For example, a high rate of dropouts (64\%) in a 60 -second long cold pressor test has been reported in an aged matched group of participants. ${ }^{37}$ However, in the present study, $87 \%$ did not withdraw their hand. Finally, it should be noted that analgesic effects of a drug may be assessed in several ways: effect on latency to pain onset; effect on peak pain intensity; effect on area under the pain intensity curve; and effect on time to threshold. ${ }^{30,38}$ Different assessments could also affect model sensitivity. ${ }^{4}$ The use of the modified rating scale was recently supported by a study with a rating scale 
ranging from "no sensation" to "unbearable pain", allowing participants to rate stimulus intensities that are perceived but are not painful, and may reduce bias and be more reliable for experimental pain assessment. ${ }^{39}$

The fact that 34 of 93 screened healthy volunteers were not willing to participate after further information and consideration indicates a study selection bias, and hence, results may not reflect the Danish population. However, as participation is voluntary, experimental pain studies will always be affected by such study selection bias.

\section{Recommendations}

Several factors should be considered when planning an experimental human pain study for assessment of analgesic effects. ${ }^{1}$ Using multi-modal tests and multi-tissue stimulations, the present study confirmed that: 1) deep stimuli should be included to mimic the clinical situation; 2) tonic stimulations should be used rather than phasic stimulations to evaluate pain intensity before and after drug administration; and 3) models involving activation predominantly of $\mathrm{C}$ fibers should be included.

\section{Conclusion}

Pain models with deep tonic stimulation including $\mathrm{C}$ fiber activation and/or endogenous pain modulation were more sensitive to morphine analgesia. To avoid false negative results in future studies, we recommend inclusion of reproducible tonic pain models in deep tissues, mimicking clinical pain to a higher degree.

\section{Acknowledgment}

The study was supported by the Danish Council for Strategic Research and Det Obelske Familiefond.

\section{Disclosure}

The funding sources for this work were not involved in the conduct of the study or in the development of the submission. The authors report no conflicts of interest in this work.

\section{References}

1. Olesen AE, Andresen T, Staahl C, Drewes AM. Human experimental pain models for assessing the therapeutic efficacy of analgesic drugs. Pharmacol Rev. 2012;64(3):722-779.

2. Staahl C, Olesen AE, Andresen T, Arendt-Nielsen L, Drewes AM. Assessing analgesic actions of opioids by experimental pain models in healthy volunteers - an updated review. Br J Clin Pharmacol. 2009;68(2): 149-168.

3. Koltzenburg M, Pokorny R, Gasser UE, Richarz U. Differential sensitivity of three experimental pain models in detecting the analgesic effects of transdermal fentanyl and buprenorphine. Pain. 2006;126(1-3):165-174.
4. Angst MS, Clark JD. Comment on Koltzenburg et al. Differential sensitivity of three experimental pain models in detecting the analgesic effects of transdermal fentanyl and buprenorphine. Pain 2006;126:165-74. Pain. 2007;128(3):292-294.

5. Petersen KL. Experimental cutaneous hyperalgesia in humans. In: Berde CB, Rowbotham MC, editors. Technical Corner from IASP Newsletter. Washington, DC: International Association for the Study of Pain; 1997.

6. Oertel BG, Lotsch J. Clinical pharmacology of analgesics assessed with human experimental pain models: Bridging basic and clinical research. Br J Pharmacol. 2012;168(3):534-553.

7. Kandel ER, Schwartz JH, Jessell TM. Part V perception. In: Kandel ER, Schwartz JH, Jessell TM, editors. Principles of Neural Science United States of America. The McGraw-Hill Publishing Company, Inc.; 2000:411-624.

8. Le Bars D, Gozariu M, Cadden SW. Animal models of nociception. Pharmacol Rev. 2001;53(4):597-652.

9. Lu Y, Pirec V, Yeomans DC. Differential antinociceptive effects of spinal opioids on foot withdrawal responses evoked by $\mathrm{C}$ fibre or A delta nociceptor activation. Br J Pharmacol. 1997;121(6):1210-1216.

10. Le Bars D, Guilbaud G, Jurna I, Besson JM. Differential effects of morphine on responses of dorsal horn lamina $\mathrm{V}$ type cells elicited by $\mathrm{A}$ and $\mathrm{C}$ fibre stimulation in the spinal cat. Brain Res. 1976;115(3):518-524.

11. Drewes AM, Gregersen H, Arendt-Nielsen L. Experimental pain in gastroenterology: a reappraisal of human studies. Scand J Gastroenterol. 2003;38(11):1115-1130.

12. Andresen T, Pfeiffer-Jensen M, Brock C, Drewes AM, Arendt-Nielsen L. A human experimental bone pain model. Basic Clin Pharmacol Toxicol. 2013;112(2):116-123.

13. Andresen T, Staahl C, Oksche A, Mansikka H, Arendt-Nielsen L, Drewes AM. Effect of transdermal opioids in experimentally induced superficial, deep and hyperalgesic pain. Br J Pharmacol. 2011;164(3): 934-945.

14. Brock C, Nissen TD, Gravesen FH, et al. Multimodal sensory testing of the rectum and rectosigmoid: development and reproducibility of a new method. Neurogastroenterol Motil. 2008;20(8):908-918.

15. Rosier EM, Iadarola MJ, Coghill RC. Reproducibility of pain measurement and pain perception. Pain. 2002;98(1-2):205-216.

16. McCormack K, Prather P, Chapleo C. Some new insights into the effects of opioids in phasic and tonic nociceptive tests. Pain. 1998;78(2):79-98.

17. Nielsen J, Arendt-Nielsen L. The influence of rate of temperature change and peak stimulus duration on pain intensity and quality. Somatosens Mot Res. 1998;15(3):220-229.

18. Handwerker HO, Kobal G. Psychophysiology of experimentally induced pain. Physiol Rev. 1993;73(3):639-671.

19. Cairns BE. Physiological properties of thin-fiber muscle afferents: excitation and modulatory effects. In: Graven-Nielsen T, Arendt-Nielsen L, Mense S, editors. Fundamentals of Musculoskeletal Pain. 1st ed. Seattle, WA: IASP Press; 2008:19-32.

20. Schulte H, Graven-Nielsen T, Sollevi A, Jansson Y, Arendt-Nielsen L, Segerdahl M. Pharmacological modulation of experimental phasic and tonic muscle pain by morphine, alfentanil and ketamine in healthy volunteers. Acta Anaesthesiol Scand. 2003;47(8):1020-1030.

21. Fields H. State-dependent opioid control of pain. Nat Rev Neurosci. 2004;5(7):565-575.

22. Mattia C, Di Bussolo E, Coluzzi F. Non-analgesic effects of opioids: the interaction of opioids with bone and joints. Curr Pharm Des. 2012;18(37):6005-6009.

23. Finocchietti S, Andresen T, Arendt-Nielsen L, Graven-Nielsen T. Pain evoked by pressure stimulation on the tibia bone - influence of probe diameter on tissue stress and strain. Eur J Pain. 2012;16(4): 534-542.

24. Byers MR, Bonica JJ. Peripheral pain mechanisms and nociceptor plasticity. In: Loeser LD, Butler SH, Chapman CR, Turk DC, editors. Bonica's Management of Pain. Philadelphia, PA: Lippincott Williams \& Wilkins; 2001. 
25. Morgan V, Pickens D, Gautam S, Kessler R, Mertz H. Amitriptyline reduces rectal pain related activation of the anterior cingulate cortex in patients with irritable bowel syndrome. Gut. 2005;54(5): 601-607.

26. Brock C, Arendt-Nielsen L, Wilder-Smith O, Drewes AM. Sensory testing of the human gastrointestinal tract. World J Gastroenterol. 2009;15(2):151-159.

27. Staahl C, Christrup LL, Andersen SD, Arendt-Nielsen L, Drewes AM. A comparative study of oxycodone and morphine in a multi-modal, tissue-differentiated experimental pain model. Pain. 2006;123(1-2): 28-36.

28. Olesen AE, Staahl C, Arendt-Nielsen L, Drewes AM. Different effects of morphine and oxycodone in experimentally evoked hyperalgesia: a human translational study. $\mathrm{Br} J$ Clin Pharmacol. 2010;70(2):189-200.

29. Arendt-Nielsen L, Andresen T, Malver LP, Oksche A, Mansikka H, Drewes AM. A double-blind, placebo-controlled study on the effect of buprenorphine and fentanyl on descending pain modulation: a human experimental study. Clin J Pain. 2012;28(7):623-627.

30. Jones SF, McQuay HJ, Moore RA, Hand CW. Morphine and ibuprofen compared using the cold pressor test. Pain. 1988;34(2):117-122.

31. Rainville P, Feine JS, Bushnell MC, Duncan GH. A psychophysical comparison of sensory and affective responses to four modalities of experimental pain. Somatosens Mot Res. 1992;9(4):265-277.

32. van der Kam EL, Vry JD, Schiene K, Tzschentke TM. Differential effects of morphine on the affective and the sensory component of carrageenan-induced nociception in the rat. Pain. 2008;136(3): 373-379.
33. Kupers RC, Konings H, Adriaensen H, Gybels JM. Morphine differentially affects the sensory and affective pain ratings in neurogenic and idiopathic forms of pain. Pain. 1991;47(1):5-12.

34. Cleeland CS, Nakamura Y, Howland EW, Morgan NR, Edwards KR, Backonja M. Effects of oral morphine on cold pressor tolerance time and neuropsychological performance. Neuropsychopharmacology. $1996 ; 15(3): 252-262$.

35. Turk DC, Dworkin RH, McDermott MP, et al. Analyzing multiple endpoints in clinical trials of pain treatments: IMMPACT recommendations. Initiative on methods, measurement, and pain assessment in clinical trials. Pain. 2008;139(3):485-493.

36. Drewes AM, Jensen RD, Nielsen LM, et al. Differences between opioids: pharmacological, experimental, clinical and economical perspectives. Br J Clin Pharmacol. 2013;75(1):60-78.

37. Ruscheweyh R, Stumpenhorst F, Knecht S, Marziniak M. Comparison of the cold pressor test and contact thermode-delivered cold stimuli for the assessment of cold pain sensitivity. J Pain. 2010;11(8):728-736.

38. Grach M, Massalha W, Pud D, Adler R, Eisenberg E. Can coadministration of oxycodone and morphine produce analgesic synergy in humans? An experimental cold pain study. Br J Clin Pharmacol. 2004;58(3):235-242.

39. Kemp J, Despres O, Dufour A. Unreliability of the visual analog scale in experimental pain assessment: a sensitivity and evoked potentials study. Pain Physician. 2012;15(5):e693-e699.
Journal of Pain Research

\section{Publish your work in this journal}

The Journal of Pain Research is an international, peer-reviewed, open access, online journal that welcomes laboratory and clinical findings in the fields of pain research and the prevention and management of pain. Original research, reviews, symposium reports, hypothesis formation and commentaries are all considered for publication.

\section{Dovepress}

The manuscript management system is completely online and includes a very quick and fair peer-review system, which is all easy to use. Visit http://www.dovepress.com/testimonials.php to read real quotes from published authors. 